\title{
Orthostatic Hypotension in Elderly Patients with Essential Tremor
}

Derya Kaya (iD) ${ }^{1}$

Ali Ekrem Aydin ${ }^{2}$

Ahmet Turan Isik (D)

'Unit for Brain Aging and Dementia, Department of Geriatric Medicine, Faculty of Medicine, Dokuz Eylül University, Izmir, Turkey; ${ }^{2}$ Department of Geriatric Medicine, Sivas State Hospital, Sivas, Turkey
Correspondence: Derya Kaya

Unit for Brain Aging and Dementia,

Department of Geriatric Medicine,

Faculty of Medicine, Dokuz Eylül

University, Balçova, Izmir 35340, Turkey

Tel +90 $232412434 \mid$

Fax +902324124339

Email deryakaya29@gmail.com
This article was published in the following Dove Press journal:

Clinical Interventions in Aging

Purpose: Essential tremor (ET) is the most common movement disorder in which dysautonomia symptoms can be present. We aimed to evaluate the presence of orthostatic hypotension $(\mathrm{OH})$ and its relationship with the clinical features.

Patients and Methods: Forty-four elderly patients with ET and 118 healthy elderly controls were included. $\mathrm{OH}$ was assessed via the head-up tilt table test and defined, according to the change in position, as a drop of at least $20 \mathrm{mmHg}$ in systolic blood pressure and/or $10 \mathrm{mmHg}$ in diastolic blood pressure. Tremor severity was evaluated using the Fahn-Tolosa-Marin Tremor Rating (FTMTR) Scale. All patients underwent geriatric comprehensive assessment.

Results: There were no differences between the controls and patients with ET regarding age and gender. The mean age was $72.8 \pm 6.1$, the mean disease duration $19.1 \pm 13.5$ years and the mean FTMTR score was $30.9 \pm 17.1$ in patients with ET. The frequency of $\mathrm{OH}$ at the 1st minute in patients with ET was higher than in controls $(31.8 \%$ vs $17.8 \%, p=0.046)$. Furthermore, the frequency of jaw tremor in patients with $\mathrm{OH}$ was higher than in those without $\mathrm{OH}(35.7 \%$ vs $6.7 \%, \mathrm{p}=0.025)$. About $28.6 \%$ of ET patients with $\mathrm{OH}$ had orthostatic symptoms.

Conclusion: We demonstrated that ET patients, particularly those with jaw tremors, had $\mathrm{OH}$ and that most of them were asymptomatic. Therefore, in order to protect patients from complications related to $\mathrm{OH}$, it would be appropriate to evaluate $\mathrm{OH}$ in the follow-up and treatment of elderly patients with ET.

Keywords: essential tremor, orthostatic hypotension, head-up tilt table test, jaw tremor, elderly

\section{Introduction}

Essential tremor (ET) is a gradual progressive movement disorder common in the elderly of 60 and above, with a prevalence of $1 \%$ to $5 \%$. It is characterized by approximately symmetrical postural or kinetic tremors in the hands and forearms, followed by head, voice and jaw tremors in some patients. ${ }^{1}$ Neuropathological studies in ET have revealed microstructural changes in the cerebellum. ${ }^{2}$ Additionally, Lewy bodies mainly in the locus coeruleus of the brainstem were detected in some patients with ET. ${ }^{3}$ The locus coeruleus is an established structure regulating autonomic responses, resulting in modulation in blood pressure and baroreflex responses. ${ }^{4}$ Besides, recent evidence suggests that the cerebellum serves to mediate cardiovascular responses, thus contributing to the cortical autonomic network which plays a significant role in controlling cardiovascular changes occurring in response to stressors like orthostatic challenges, such as orthostatic hypotension $(\mathrm{OH}) .^{5-7}$ 
$\mathrm{OH}$, also accepted as a geriatric syndrome, can lead to several negative health outcomes in the elderly, such as increasing the risk of falls and fractures, cerebrocardiovascular morbidity, and inability to perform activities of daily living. ${ }^{8,9}$ Therefore, screening of $\mathrm{OH}$ in elderly ET patients is of great importance in geriatric practices. Kim et al reported that ET cases displayed more orthostatic symptoms than controls but the frequency of $\mathrm{OH}$ in younger ET patients was similar to that of normal controls. ${ }^{10}$ Nonetheless, Damian et al found that with the exception of sialorrhea, there were no autonomic symptoms in ET cases. ${ }^{11}$ Thus, the issue of autonomic dysfunction in ET cases is still a topic of debate and reports addressing $\mathrm{OH}$ in the cases are scarce. Provided that both cardiovascular autonomic functions such as postural control of blood pressure and the source of the pathophysiology of ET appear to involve pathways through the cerebellum and locus coeruleus, certain questions arise such as "Can autonomic functions be affected in ET?" or "Can postural blood pressure changes be associated with ET in the elderly?"

Therefore, the objective of the current study was to investigate whether, in comparison to normal controls, patients with ET experience $\mathrm{OH}$ during postural changes in the Head-up Tilt Table (HUT) test, and to explore the clinical features of ET cases with $\mathrm{OH}$.

\section{Participants and Methods}

\section{The Study Population}

ET and healthy controls were included in this crosssectional study. All participants were patients who had been admitted to the outpatient clinic at the Department of Geriatric Medicine in Dokuz Eylul University, Faculty of Medicine, Izmir, Turkey, during the period from December 2018 to December 2019. The study was approved by the local ethics committee of the University and was conducted in accordance with the Helsinki Declaration. Written informed consent was obtained from all study participants.

All patients were clinically diagnosed with ET based on recommendations of the Consensus Statement of the Movement Disorders Society. ${ }^{1}$ Patients who had no history of movement disorders, dementia, psychiatric disorders, no family history of ET or other neurodegenerative diseases, or no evidence of vascular or other brain lesions on a standard structural CT scan in our outpatient clinic were included as a control group.
Participants who were not eligible for assessment of orthostatic blood pressure change, including severe anemia (hemoglobin $<10 \mathrm{~g} / \mathrm{dL}$ ), critical mitral and/or aortic valve stenosis, acute or chronic renal insufficiency, decompensated cardiac and/or hepatic insufficiency, severe carotid artery stenosis and/or severe coronary artery disease (CAD), acute myocardial infarction, dehydration, and electrolyte imbalances were excluded from the study. Additionally, participants who had been receiving digoxin, thyroxine, dopaminergic medications and/or anticholinergic treatment and those with laboratory abnormalities in thyroid function, hepatic function and renal function were also excluded.

\section{Comprehensive Geriatric Assessment (CGA)}

Demographic features, physical examinations, neurological examinations, and a set of scales were obtained from the medical records. The demographic features were gender, age, family history of ET, medical and medication history, neurological history, and educational history. A family history of ET was defined as the presence of at least one first-degree relative with reported ET. The number of medications and the Charlson Comorbidity Index (CCI) were recorded. The set of scales included the MiniMental State Examination (MMSE) test for global cognitive evaluation, ${ }^{12,13}$ the Geriatric Depression Scale (GDS), ${ }^{14}$ the timed-up-and-go (TUG) test, ${ }^{15}$ the Tinetti Performance Oriented Mobility Assessment (POMA), ${ }^{16}$ and Basic and Instrumental Activities of Daily Living (BADL and IADL). ${ }^{17,18}$ Tremor severity was measured using the Fahn-Tolosa-Marin Tremor Rating (FTMTR) Scale in ET cases. ${ }^{19}$

\section{Evaluation of Orthostatic Hypotension}

The standardized tilt table was used (Gemesan ${ }^{\circledR}$ Tilt Table G-71, Istanbul, Turkey) in the HUT test. All participants were allowed to take their daily medications and warned not to smoke, drink caffeine, or drink alcoholic beverages. They were seated with a minimum of 1-hour pre- or postlunch before the measurements were obtained. BP measurement was taken following 30 minutes of rest in a reclining position in a silent room at a controlled temperature of $20-24^{\circ} \mathrm{C}$; then the patients were raised upright at $60-80^{\circ}$ rapidly and fluently and the measurements were repeated for the same arm on the 1st, 3rd, and 5th minutes using a patient monitor (Biolight ${ }^{\mathbb{R}}$, BIOM69, Australia) 
with a reusable adult arm cuff. ${ }^{8}$ During the HUT, the patients were questioned concerning $\mathrm{OH}$ symptoms such as dizziness, lightheadedness, blackout, nausea, etc. $\mathrm{OH}$ was defined as a decrease of at least $20 \mathrm{mmHg}$ in systolic blood pressure and/or $10 \mathrm{mmHg}$ in diastolic blood pressure upon the change in position in the HUT. ${ }^{20,21}$

\section{Statistical Analysis}

The study data were analyzed using SPSS v 22.0 (IBM Corp, U.S.A.). The descriptive statistics have been shown as mean \pm standard deviation (SD) for variables with normal distribution, median (minimum to maximum) for non-normal distributions, and number of cases and percentage (\%) for nominal variables. The Kolmogorov-Smirnov test was performed to test the normality of continuous variables. Differences in categorical variables between patients with ET and the controls were tested using the chisquare test, or Fisher's exact test when the assumptions for chi-square test were unmet. All comparisons of continuous variables between the two independent groups were performed with the Mann-Whitney $U$-test. Binary logistic regression analysis was conducted to determine whether there was a relationship between significant variables, resulting from the comparisons between the groups, and $\mathrm{OH}$. A probability of $<0.05$ was described as significant. In patients with ET, the correlation between the clinical parameters and the decrease in blood pressure obtained from the HUT was analyzed via the Spearman correlation coefficient. Only correlations which were statistically significant, and represented large-effect sizes, as defined by a correlation coefficient of 0.50 or higher, were presented in the results and considered for discussion.

\section{Results}

The demographic data and clinical characteristics of the controls $(n=118)$ and patients with ET $(n=44)$ have been summarized in Table 1. There was no difference between the groups with respect to age and gender.

The number of subjects with $\mathrm{OH}$ at the 1st minute after tilting was significantly higher in patients with ET than in controls (14 of 44 vs 21 of 118 patients, $p=0.046$ ). However, the presence of $\mathrm{OH}$ both at the $3 \mathrm{rd}$ minute and the 5th minute was similar in subjects with ET and controls ( $p=0.484$ and 0.918 , respectively). CAD and the usage of beta-blockers and antidepressants were significantly more prevalent in patients with ET than in controls $(\mathrm{p}=0.001, \quad 0.001,0.046$, respectively) (Table 1). Subsequently, binary logistic regression analysis was used to analyze whether the use of beta-blockers, antidepressants, and $\mathrm{CAD}$ had any relationship with $\mathrm{OH}$ at the 1st minute. The results indicated that the difference in $\mathrm{OH}$ was not related to these covariates in patients with ET $(\mathrm{p}=$ $0.528,0.980$ and 0.054 , respectively).

The mean disease duration was $19.1 \pm 13.5$ years (range: 5-55) and the mean FTMTR score was 30.9 \pm 17.1 (range: 4-63) in patients with ET. Family history was positive in $81.8 \%$ of 44 patients, voice tremors in 16 patients $(36.4 \%)$, head tremors in nine patients $(20.5 \%)$, and jaw tremors in seven patients $(15.9 \%)$. There were no significant differences between ET patients with and without $\mathrm{OH}$ regarding age, gender, disease durations, and FTH scores and tremor localizations including the head and voice. However, the frequency of jaw tremors in patients with $\mathrm{OH}$ was higher than those without $\mathrm{OH}(35.7 \%$ vs $6.7 \%, \mathrm{p}=0.025)$. In other words, most of the patients with jaw tremors had $\mathrm{OH}(5 / 7)$. The comparison data of ET patients with and without $\mathrm{OH}$ has been presented in Table 2. Only four (28.6\%) out of 14 ET patients with $\mathrm{OH}$ complained of feeling dizzy or lightheaded while standing.

In the ET patients with $\mathrm{OH}$ group, Spearman correlation analysis revealed that the decrease in systolic blood pressure (SBP) upon the change from the supine position to the upright at the 1 st minute in the HUT ( $\triangle$ SBP) was correlated with age $(r=0.560, p=0.038)$ and with MMSE scores $(r=-0.690, p=0.009)$.

\section{Discussion}

This cross-sectional study demonstrated that the frequency of $\mathrm{OH}$ in elderly patients with ET was higher than healthy controls and that the majority of those with ET did not exhibit orthostatic symptoms. Moreover, most of the patients with jaw tremors had $\mathrm{OH}$.

The frequency of $\mathrm{OH}$ has not been studied sufficiently in the literature. Kim et $\mathrm{al}^{10}$ reported it to be $12 \%$, whereas the frequency was shown to be $32 \%$ of our study population. This discrepancy between both studies may be related to the differences such as the methodological approach and features of the patient groups. Compared to ours, the patients studied by Kim et al ${ }^{10}$ were younger with shorter disease durations. It is known that age is a risk factor for both hypertension (HT) and $\mathrm{OH}$, and they often coexist due to their relation to autonomic and baroreflex dysfunctions. $^{22}$ The prevalence of HT, an important cause of $\mathrm{OH}$, in patients 60 years of age and above was reported as approximately $60-70 \% .^{23}$ Consequently, it is not surprising that the ET patients in the aforementioned 
Table I Demographic and Clinical Characteristics of the Participants in the Study

\begin{tabular}{|l|l|l|l|}
\hline & ET $\mathbf{n = 4 4}$ & Healthy Controls n=I I 8 & p \\
\hline Age (y) & $72.8 \pm 6.1$ & $72.7 \pm 6.7$ & $0.97 \mid$ \\
Gender female n (\%) & $30(68.2)$ & $94(79.7)$ & 0.125 \\
Hypertension (\%) & 72.7 & 61.9 & 0.135 \\
Diabetes mellitus (\%) & 22.7 & 31.4 & 0.282 \\
Coronary artery disease (\%) & 34.1 & 11 & $\mathbf{0 . 0 0 1}$ \\
Charlson Comorbidity Index & $0.95 \pm 0.83$ & $0.85 \pm 1.01$ & 0.239 \\
Drugs (n) & $5.2 \pm 2.8$ & $5.0 \pm 3.4$ & 0.465 \\
OH Ist n, (\%) & $14(31.8)$ & $21(17.8)$ & $\mathbf{0 . 0 4 6}$ \\
OH 3rd n, (\%) & $12(27.3)$ & $26(22)$ & 0.484 \\
OH 5th n, (\%) & $10(22.7)$ & $25(21.2)$ & 0.918 \\
HBAIC (\%) & $6.8 \pm 1.1$ & $7.3 \pm 1.8$ & 0.684 \\
TSH (mlU/L) & $1.8 \pm 1.1$ & $1.7 \pm 1.5$ & 0.473 \\
Beta blockers (\%) & 59.1 & 30.5 & $\mathbf{0 . 0 0 1}$ \\
Antihypertensive drugs* (\%) & 68.3 & 58.1 & $0.25 \mathrm{I}$ \\
SSRI (\%) & 45.5 & 28.8 & $\mathbf{0 . 0 4 6}$ \\
\hline
\end{tabular}

Notes: *Includes calcium channel blockers, diüretic, ACE inhibitors, ARB inhibitors. Statistically significant differences are shown bold and the significance level is 0.05 . Abbreviations: ET, essential tremor; n, number; $\mathrm{OH}$, orthostatic hypotension; \%, percent; SSRI, selective serotonin reuptake inhibitors; TSH, thyroid-stimulating hormone; y, years.

Table 2 The Demographic and Clinical Features of Patients with Essential Tremor

\begin{tabular}{|c|c|c|c|}
\hline & OH (+) $n=14$ & $\mathrm{OH}(-) n=30$ & $\mathbf{P}$ \\
\hline Age $(y)$, mean $\pm S D$ & $74.5 \pm 5.2$ & $72 \pm 6.5$ & 0.300 \\
\hline Gender M n, (\%) & $6(42.9)$ & $8(26.7)$ & 0.232 \\
\hline Disease duration $(\mathrm{y})$, mean \pm SD & $|4| \pm 8.7$. & $19.7 \pm 13.7$ & 0.343 \\
\hline FTMTR scale* & $38(6-60)$ & $30(4-63)$ & 0.314 \\
\hline Family history of ET (\%) & $13(92.9)$ & $23(76.7)$ & $0.194 * *$ \\
\hline Voice tremor (\%) & $3(21.4)$ & $13(43.3)$ & 0.159 \\
\hline Head tremor (\%) & $3(21.4)$ & $6(20)$ & $0.603 *$ \\
\hline Jaw tremor (\%) & $5(35.7)$ & $2(6.7)$ & $0.025 * *$ \\
\hline MMSE* & $28(25-30)$ & $28(22-30)$ & 0.802 \\
\hline Geriatric Depression Scale* & $2(0-12)$ & $2(0-12)$ & 0.724 \\
\hline Basic ADL score* & $95(80-100)$ & $95(75-100)$ & 0.927 \\
\hline Instrumental ADL score* & $22(I I-23)$ & $22(13-13)$ & 0.557 \\
\hline 4-meter-walking speed $\mathrm{m} / \mathrm{sec}^{*}$ & I $(0.8-1.33)$ & $0.96(0.38-1.73)$ & 0.973 \\
\hline TUG test, seconds* & $11.89(7-22)$ & II (6-24) & 0.485 \\
\hline POMA-total score* & $27(19-28)$ & $28(14-28)$ & 0.333 \\
\hline Beta-blockers n (\%) & $9(64.3)$ & $17(56.7)$ & 0.632 \\
\hline
\end{tabular}

Notes: Statistically significant differences are shown bold and the significance level is 0.05 . *Median (minimum-maximum); **Fisher's exact test.

Abbreviations: ADL, activities of daily living; FTMTR Fahn-Tolosa-Marin Tremor Rating Scale; M, male; MMSE, mini-mental state examination test; POMA, Tinetti Performance-Oriented Mobility Assessment; SD, standard deviation; TUG, timed up and go test; y, years.

study, with a lower prevalence of HT ( $40 \%$ of their ET patients had HT and $16 \%$ of the 25 controls), exhibited lower frequencies of $\mathrm{OH}$. In addition, the discontinuation of the patient's antihypertensive medications 7 days before evaluating postural blood pressure changes may have been the reason behind this difference observed in that study.

Interestingly, in our study, approximately $36 \%$ of ET patients with $\mathrm{OH}$ experienced jaw tremors, a type of midline tremor, while it was observed in only $7 \%$ of the patients without $\mathrm{OH}$. Hence, it is reasonable to investigate every ET patient, in terms of $\mathrm{OH}$, particularly those with midline tremors, because we demonstrated that patients with jaw tremors, who had been suffering for 10 years, displayed higher scores on the tremor severity scale, and also had tremors of the head and/or voice, and might have more $\mathrm{OH}$ than those without jaw tremors. Furthermore, 
considering that jaw tremors shared the same underlying pathophysiology of tandem gait difficulty in $\mathrm{ET},{ }^{24}$ it can be postulated that cerebellar dysregulation seems to be critical in the development of midline tremors. Additionally, considerable evidence suggests that control of postural blood pressure changes also involves pathways through the cerebellum of which disruption may result in deficits in adjustments during postural changes. ${ }^{7,25,26}$ Consequently, cerebellar dysregulation may become prominent in explaining the underlying pathophysiology of $\mathrm{OH}$, at least, in patients with jaw tremors.

In addition to reduced GABAergic function within the locus coeruleus, and adrenergic changes following GABAergic dysfunction in ET patients, ${ }^{27}$ it can also be posited that autonomic dysfunction, such as $\mathrm{OH}$, may be a result of this secondary locus coeruleus-noradrenergic deterioration in these patients. Nevertheless, these hypotheses need to be confirmed in the autopsy series of ET patients with and without $\mathrm{OH}$.

Several studies indicated that both ET and $\mathrm{OH}$ are related to cognitive impairment. ${ }^{28-30}$ The present study demonstrated that the decrease in the systolic blood pressure within the 1st minute was correlated with lower MMSE scores. This may have been due to the fact that $\mathrm{OH}$ in SBP was commonly reported to be related to cerebrovascular events and vascular cognitive impairment. ${ }^{31-33}$ Nevertheless, prospective follow-up studies are needed to clarify this link between cognitive dysfunction in patients with $\mathrm{OH}$ and ET.

The unique aspect of this study is that, to the best of our knowledge, it is the first study of its kind to evaluate $\mathrm{OH}$ with HUT in elderly patients with ET. Also, all the patients underwent comprehensive geriatric assessment including clinical and neuropsychological assessment and $\mathrm{OH}$ was objectively evaluated using the HUT which is known to reveal satisfactory results on postural blood pressure changes. Furthermore, since patients with several comorbidities were included in the study, our results reflect real-life characteristics of older patients with ET. However, this study has a few limitations such as its retrospective design and small sample size.

\section{Conclusion}

To sum up, it appears that $\mathrm{OH}$ is a common accompanying condition in elderly patients with ET, particularly for those with jaw tremors, and as it is asymptomatic in most, it might be related to cognitive impairment in these patients. In addition, considering the potential complications of $\mathrm{OH}$, it would be appropriate to evaluate $\mathrm{OH}$ in the follow-up and treatment of elderly patients with ET. In order to thoroughly evaluate the interrelationship between $\mathrm{OH}$ and ET in elderly patients, further longitudinal studies are needed.

\section{Disclosure}

The authors report no conflict of interest in this work.

\section{References}

1. Deuschl G, Bain P, Brin M. Consensus statement of the movement disorder society on tremor. Ad Hoc Scientific Committee. Mov Disord. 1998;13(Suppl 3):2-23. doi:10.1002/mds.870131303

2. Babij R, Lee M, Cortés E, Vonsattel JP, Faust PL, Louis ED. Purkinje cell axonal anatomy: quantifying morphometric changes in essential tremor versus control brains. Brain. 2013;136:3051-3061. doi:10.1093/brain/ awt 238

3. Louis ED, Faust PL, Vonsattel JP, et al. Neuropathological changes in essential tremor: 33 cases compared with 21 controls. Brain. 2007;130(Pt12):3297-3307. doi:10.1093/brain/awm266

4. Samuels ER, Szabadi E. Functional neuroanatomy of the noradrenergic locus coeruleus: its roles in the regulation of arousal and autonomic function part II: physiological and pharmacological manipulations and pathological alterations of locus coeruleus activity in humans. Curr Neuropharmacol. 2008;6(3):254-285. doi:10.2174/ 157015908785777193

5. Shoemaker JK, Goswami R. Forebrain neurocircuitry associated with human reflex cardiovascular control. Front Physiol. 2015;6:1-14. doi:10.3389/fphys.2015.00240

6. Baker J, Paturel JR, Kimpinski K. Cerebellar impairment during an orthostatic challenge in patients with neurogenic orthostatic hypotension. Clin Neurophysiol. 2019;130:189-195. doi:10.1016/j. clinph.2018.07.026

7. Baker J, Kimpinski K. Evidence of impaired cerebellar connectivity at rest and during autonomic maneuvers in patients with autonomic failure. Cerebellum. 2020;19(1):30-39. doi:10.1007/s12311-019-01076-8

8. Aydin AE, Soysal P, Isik AT. Which is preferable for orthostatic hypotension diagnosis in older adults: active standing test or head-up tilt table test? Clin Interv Aging. 2017;12:207-212. doi:10.2147/CIA.S129868

9. Soysal P, Veronese N, Smith L, et al. Orthostatic hypotension risk factors and health outcomes: an umbrella review of observational studies. Eur Geriatr Med. 2019;10:863-870. doi:10.1007/s41999019-00239-4

10. Kim JS, Oh YS, Park HE, et al. Cardiovascular autonomic dysfunctions in elderly patients with essential tremor: comparison with healthy controls. Neurol Sci. 2016;37(5):711-716. doi:10.1007/ s10072-015-2465-x

11. Damian A, Adler CH, Hentz JG, et al. Autonomic function, as selfreported on the SCOPA-autonomic questionnaire, is normal in essential tremor but not in Parkinson's disease. Parkinsonism Relat Disord. 2012;18(10):1089-1093. doi:10.1016/j.parkreldis.2012.06.008

12. Folstein MF, Folstein SE, McHugh PR. "Mini-mental state". A practical method for grading the cognitive state of patients for the clinician. J Psychiatr Res. 1975;12:189-198. doi:10.1016/00223956(75)90026-6

13. Gungen C, Ertan T, Eker E, Yasar R, Engin F. Reliability and validity of the standardized Mini Mental State Examination in the diagnosis of mild dementia in Turkish population. Turk Psikiyatri Derg. 2002;13:273-281.

14. Durmaz B, Soysal P, Ellidokuz H, Isik AT. Validity and reliability of geriatric depression scale - 15 (Short Form) in Turkish older adults. North Clin Istanbul. 2017. doi:10.14744/nci.2017.85047 
15. Podsiadlo D, Richardson S. The timed 'Up \& Go': A test of basic functional mobility for frail elderly persons. $J$ Am Geriatr Soc. 1991;39:142-148. doi:10.1111/j.1532-5415.1991.tb01616.x

16. Tinetti ME. Performance-oriented assessment of mobility problems in elderly patients. J Am Geriatr Soc. 1986;34:119-126. doi:10.1111/ j.1532-5415.1986.tb05480.x

17. Lawton M, Brody E. Assessment of older people: self-maintaining and instrumental activities of daily living. Gerontologist. 1969;9:179-186. doi:10.1093/geront/9.3_Part 1.179

18. Mahoney FI, Barthel DW. Functional evaluation: the Barthel index. Md State Med J. 1965;14:61-65.

19. Fahn S, Tolosa E, Marin C. Clinical rating scale for tremor. In: Jankovic J, Tolosa E, editors. Parkinson's Disease and Movement Disorders. Baltimore, MD: Williams and Wilkins; 1993:271-280.

20. Parry SW, Reeve P, Lawson J, et al. The Newcastle protocols 2008: an update on head-up tilt table testing and the management of vasovagal syncope and related disorders. Heart. 2009;95 (5):416-420. doi:10.1136/hrt.2007.136457

21. Shibao C, Lipsitz LA, Biaggioni I; American Society of Hypertension Writing Group. Evaluation and treatment of orthostatic hypotension. J Am Soc Hypertens. 2013;7(4):317-324. doi:10.1016/j.jash.2013.04.006

22. Biaggioni I. Orthostatic hypotension in the hypertensive patient. $\mathrm{Am}$ J Hypertens. 2018;31(12):1255-1259. doi:10.1093/ajh/hpy089

23. Fagard RH. Epidemiology of hypertension in the elderly. Am J Geriatr Cardiol. 2002;11(1):23-28. doi:10.1111/j.1076-7460.2002.00856.x

24. Louis ED, Rios E, Rao AK. Tandem gait performance in essential tremor: clinical correlates and association with midline tremors. Mov Disord. 2010;25(11):1633-1638. doi:10.1002/mds.23144

25. Harper RM, Gozal D, Bandler R, Spriggs D, Lee J, Alger J. Regional brain activation in humans during respiratory and blood pressure challenges. Clin Exp Pharmacol Physiol. 1998;25:483-486. doi:10.1111/j.1440-1681.1998.tb02240.x
26. Nisimaru N, Okahara K, Yanai S. Cerebellar control of the cardiovascular responses during postural changes in conscious rabbits. Neurosci Res. 1998;32:267-271. doi:10.1016/S0168-0102(98) 00094-7

27. Shill HA, Adler CH, Beach TG, et al. Brain biochemistry in autopsied patients with essential tremor. Mov Disord. 2012;27(1):113-117. doi: $10.1002 / \mathrm{mds} .24004$

28. Bermejo-Pareja F. Essential tremor - a neurodegenerative disorder associated with cognitive defects? Nat Rev Neurol. 2011;7 (5):273-282. doi:10.1038/nrneurol.2011.44

29. Bermejo-Pareja F, Louis ED, Benito-Leon J; Neurological Disorders in Central Spain (NEDICES) Study Group. Risk of incident dementia in essential tremor: a population-based study. Mov Disord. 2007;22 (11):1573-1580. doi:10.1002/mds. 21553

30. Freeman R, Abuzinadah AR, Gibbons C, Jones P, Miglis MG, Sinn DI. Orthostatic hypotension: JACC state-of-the-art review. J Am Coll Cardiol. 2018;72(11):1294-1309. doi:10.1016/j. jacc.2018.05.079

31. Ballard C, O'Brien J, Barber B, et al. Neurocardiovascular instability, hypotensive episodes, and MRI lesions in neurodegenerative dementia. Ann N Y Acad Sci. 2000;903:442-445. doi:10.1111/ j.1749-6632.2000.tb06396.x

32. Yatsuya H, Folsom AR, Alonso A, Gottesman RF, Rose KM; ARIC Study Investigators. Postural changes in blood pressure and incidence of ischemic stroke subtypes: the ARIC study. Hypertension. 2011;57 (2):167-173. doi:10.1161/HYPERTENSIONAHA.110.161844

33. Isik AT, Kocyigit SE, Kaya D, et al. The relationship between the most common subtypes of dementia and orthostatic hypotension in older adults. Dement Geriatr Cogn Disord. 2021. doi:10.1159/ 000512393
Clinical Interventions in Aging

\section{Publish your work in this journal}

Clinical Interventions in Aging is an international, peer-reviewed journal focusing on evidence-based reports on the value or lack thereof of treatments intended to prevent or delay the onset of maladaptive correlates of aging in human beings. This journal is indexed on PubMed Central, MedLine, CAS, Scopus and the Elsevier

\section{Dovepress}

Bibliographic databases. The manuscript management system is completely online and includes a very quick and fair peer-review system, which is all easy to use. Visit http://www.dovepress.com/ testimonials.php to read real quotes from published authors. 